\title{
Preliminary analysis of tower crane as a type of truss structure
}

\author{
Slavomir Hric ${ }^{1, *}$, Jozef Tkac $^{1}$ Darina Matiskova ${ }^{1}$, Milan Micko ${ }^{1}$, Dusan Mandulak ${ }^{2}$ \\ ${ }^{1}$ TU Kosice, Faculty of manufacturing technologies with the seat in Presov, Sturova 31, 08001 \\ Presov, Slovakia \\ ${ }^{2}$ 1.PN, Ltd., Lubochnianska 2407/2, 08006 Presov, Slovakia
}

\begin{abstract}
Truss structures are part not only technical practice but also our everyday life. It is very important to be designed safely. One of the tools that help a designer to avoid errors and to make the right decisions about a structure material, beam profile, shape of rod construction, etc. is virtual analysis. The article deals with the preliminary study of tower crane, which can be considered as the truss structure. Various types of structures are described in the introduction. The main part of the article is devoted to static analysis of the crane. The physical 3D model was prepared in reduced scale according to standards of European model trains NEM (Normen Europäischer Modellbahnen). Axial forces, stresses in beams, as well as the maximum possible load have been specified by analytical method. The strain analysis of crane has shown that the primary design of the structure was not acceptable and the construction would not be able to lift up required weight. Results were verified by virtual simulation in software Robot Structural Analysis. Therefore, the truss was reinforced by additional bars and newly remodelled tower crane has been tested to specify the maximum load of external weight.
\end{abstract}

\section{Introduction}

Truss structures are very strength, suitable and cost-effective possibility for designing various frames and skeletons. An effectivity of the structure is measured by implemented work or by spent material amount. In order to maximize a suitable beam type, a right material and beam geometry should be chosen for the design.

Truss systems are special systems of elements/bodies that are used in the design of large-scale load-bearing structures in bridge and building construction. They enable economical construction of e.g. bridges, cranes, masts and roof constructions. The beam system consists of rods (slender bodies) which are connected by their ends in joints. According to the number of members connected in the joint, the double, triple and multiple joints can be differentiated. In order to meet the requirements of the theoretically defined 1D member system, the members must be designed sufficiently rigid [1,2].

The aim of the static solution of truss structures is to investigate external reactions in the beam system and to determine the magnitude and sense of forces transmitted by individual beams under the action of the given forces [3].

\footnotetext{
* Corresponding author: $\underline{\text { slavomirhric } @ \text {,gmail.com }}$
} 


\section{Static analysis of a tower crane}

\subsection{Verification of boundary conditions}

Theoretically defined beam system representing the mechanical (computational) model of a truss system is composed of intangible unloaded binary members with two rotational constraints connected to each other by their ends in joints, which are considered to be ideal joints. The external load of such a system is only in the joint, i.e. the action forces act on the system in the joints. These characteristics of the mechanical model of the beam system guarantee that the individual beam members of the system only transmit the forces whose carriers lie on the junction of the centres of the joins. If the members are straight, they transmit so-called axial forces that exert tension or pressure in the members. According to the spatial arrangement of beams, the mechanical models of beam systems are divided into planar and spatial ones $[4,5,6]$.

The practical design of the beam structures differs from the theoretical assumption in the first place in the way of connecting the rods because it is not performed by ideal joints. The real connection of the rods, respectively the designs of the joints can be riveted, screwed, welded, or they can be realized by joint. The real joining of the members must be done in such a way that the axes of all connected members intersect at one point [7].

Due to verification of the authors computer skills in software Robot Structural Analysis, the simple planar structure loaded by three separate forces (Figure 1), was investigated by analytical method.

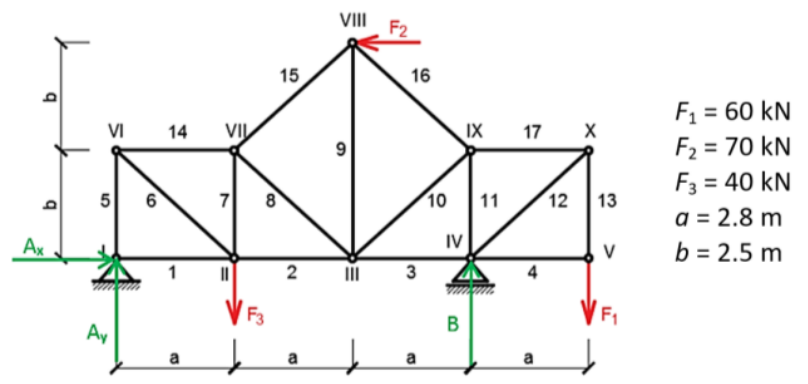

Fig. 1. Simple planar truss designed for the verification of boundary conditions.

Firstly, the external force reactions A and B (in the joints I and IV) have been calculated and in next step the equilibrium equations for each joint were written. The set of the equations has been solved in a classical computational way using a matrix as a mathematical tool. The examples of the equilibrium equations for joints II and VIII are represented by the following relations $(1)-(4)$ :

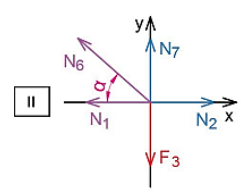

$$
\begin{aligned}
& \sum F_{i x}=0 ; \quad N_{2}-N_{1}-N_{6} \cdot \cos \alpha=0 \\
& \sum F_{i y}=0 ; \quad N_{7}-F_{3}+N_{6} \cdot \sin \alpha=0
\end{aligned}
$$

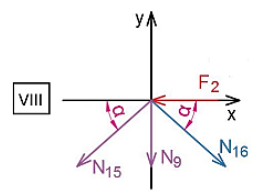

$$
\begin{aligned}
& \sum F_{i x}=0 ; \quad N_{16} \cdot \cos \alpha-F_{2}-N_{15} \cdot \cos \alpha=0 \\
& \sum F_{i y}=0 ; \quad-N_{16} \cdot \sin \alpha-N_{9}-N_{15} \cdot \sin \alpha=0
\end{aligned}
$$


The same truss has been designed in software Robot Structural Analysis due to the fact that software uses the Building Information Model technology, which now belongs to the most progressive and fastest evolving methods of complex model of the structures [8]. The system allows to create models of different types of constructions such as Frame 2D and 3D design, Volumetric Structure Design, Grillage Design, Shell Design, Building Design, etc. It was selected a tool "Truss 2D design" for preparing investigated plane truss. Analysis results has been viewed in graphical (Figure 2) and tabular form.

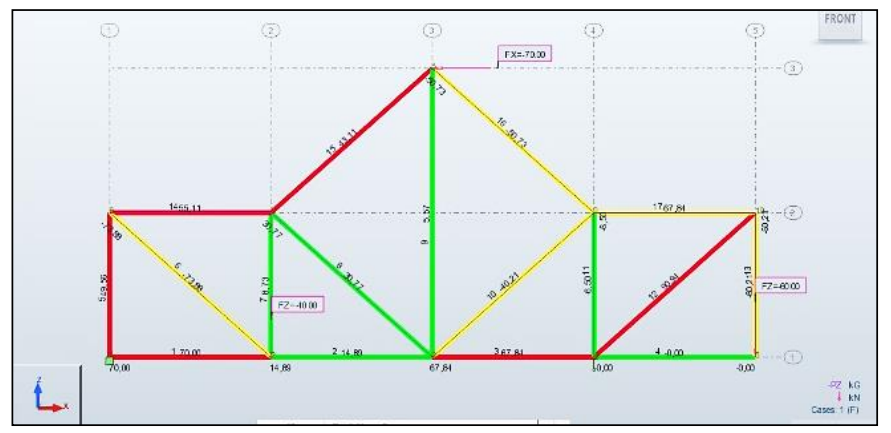

Fig. 2. Simple planar truss in software Robot Structural Analysis.

The example of axial forces of individual bars obtained by means of both analytical and computer aid methods are presented in Table 1.

Table 1. Comparison of forces in individual bars.

\begin{tabular}{|c|c|c|c|}
\hline \multicolumn{2}{|c|}{$\begin{array}{c}\text { Analytical } \\
\text { solution }(\mathrm{kN})\end{array}$} & \multicolumn{2}{c|}{$\begin{array}{c}\text { Solution with } \\
\text { computer aid } \\
(\mathrm{kN})\end{array}$} \\
\hline $\boldsymbol{A}_{\boldsymbol{x}}$ & 70 & $\boldsymbol{A}_{\boldsymbol{x}}$ & 70 \\
\hline $\boldsymbol{A}_{\boldsymbol{y}}$ & 48.33 & $\boldsymbol{A}_{\boldsymbol{y}}$ & 49.77 \\
\hline $\boldsymbol{B}$ & 51.67 & $\boldsymbol{B}$ & 54.55 \\
\hline $\boldsymbol{N}_{\mathbf{1}}$ & 70 & $\boldsymbol{N}_{\mathbf{1}}$ & 70 \\
\hline $\boldsymbol{N}_{\mathbf{2}}$ & 15.87 & $\boldsymbol{N}_{\mathbf{2}}$ & 14.89 \\
\hline $\boldsymbol{N}_{\mathbf{3}}$ & 67.20 & $\boldsymbol{N}_{\mathbf{3}}$ & 67.84 \\
\hline $\boldsymbol{N}_{\mathbf{4}}$ & 0 & $\boldsymbol{N}_{\mathbf{4}}$ & 0 \\
\hline $\boldsymbol{N}_{\mathbf{5}}$ & 48.33 & $\boldsymbol{N}_{\mathbf{5}}$ & 49.56 \\
\hline $\boldsymbol{N}_{\mathbf{6}}$ & -72.57 & $\boldsymbol{N}_{\mathbf{6}}$ & -73.88 \\
\hline $\boldsymbol{N}_{\mathbf{7}}$ & 8.33 & $\boldsymbol{N}_{\mathbf{7}}$ & 8.73 \\
\hline $\boldsymbol{N}_{\mathbf{8}}$ & 30.03 & $\boldsymbol{N}_{\mathbf{8}}$ & 30.77 \\
\hline $\boldsymbol{N}_{\mathbf{9}}$ & 5.83 & $\boldsymbol{N}_{\mathbf{9}}$ & 5.57 \\
\hline $\boldsymbol{N}_{\mathbf{1 0}}$ & -38.78 & $\boldsymbol{N}_{\mathbf{1 0}}$ & -40.21 \\
\hline
\end{tabular}

\subsection{Static analysis of a tower crane}

Tower cranes are devices that are used for vertical and horizontal handling of the load. They can be used in every industry, most often in the civil engineering industry. The history of the use of the first cranes has dated until BC, but the history of cranes as we know them today dates only to 1949 when Hans Liebherr introduced the first self-erecting tower crane.

The crane structure is a spatial truss structure which must be resistant to the load of the entire crane (base crane structure, load, cab, etc.) and side effects (operating shocks, wind, etc.). This results in requirements for the construction of the crane, which must be sufficiently rigid, strong, light, safe, yet cheap to manufacture and to transport easily [9]. 
A working arm is long horizontal jib that is part of a crane carrying a load. There is a trolley connected to the jib that moves the load along the arm. To the trolley is attached a hook that includes motor to be the load lifting controlled. The engines and electronics of the crane, as well as large counterweight weights are located on the shorter arm. The motors that drive the rotary unit are located above the large unit transmission. The hook is placed on a long horizontal arm for lifting the load, which also includes its engine.

At the designing of the crane it is important to what loads are safe and what loads are accidents waiting to happen. It is also important to consider how the crane will be moving, how often it will be used, and how it will be supported. [10]

Studied tower crane, type POTAIN E10-14C, was made from plastics according to standardized norms of European model trains NEM (Normen Europäischer Modellbahnen) in reduced scale 1:87. It is shown in Fig. 3.
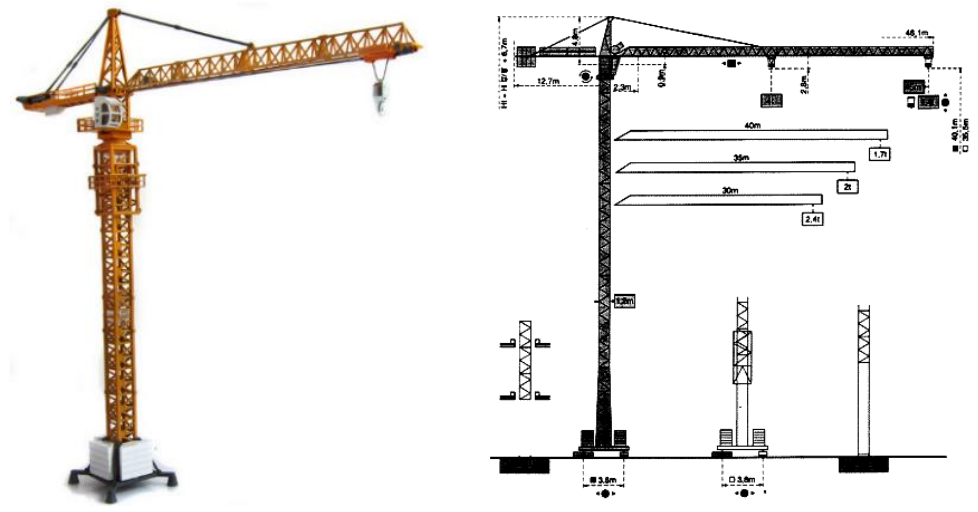

Fig. 3. Designed tower crane made as a physical model in reduced scale.

Axial forces, stress in the beams, as well as the maximum possible load have been specified by analytical method using basic principles for static equilibrium of the crane. The strain analysis of crane has shown that the primary design of the structure was not acceptable and the construction would not be able to lift up required weight. To study more precisely the structure, in the next step the crane was modelled in software Autodesk Robot Structural Analysis, as it is seen in Fig. 4.
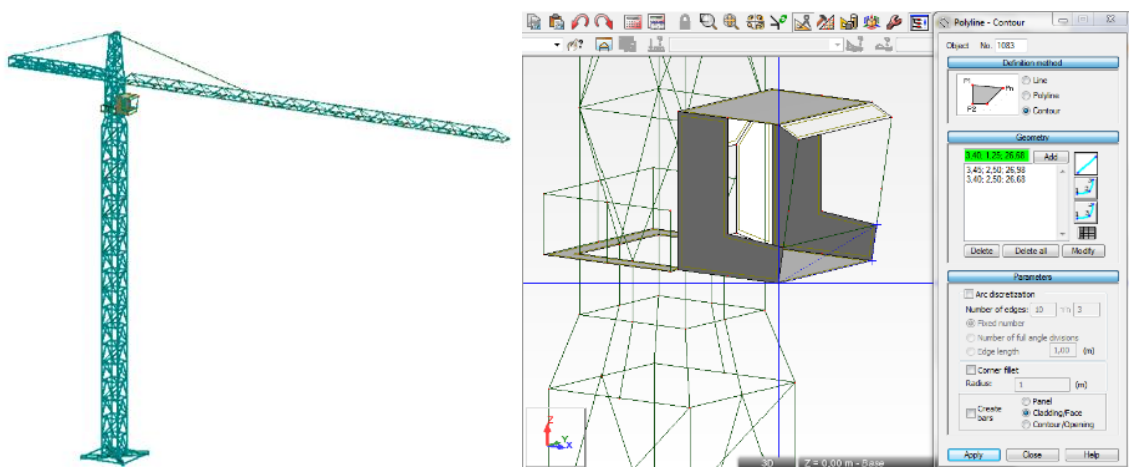

Fig. 4. Virtual model of the tower crane created in software Robot Structural Analysis.

Closed square profiles of cross-section of bars, type 50x50x3 mm (EN 10219), and type I $305 \times 165 \times 40 \mathrm{~mm}$ for the beams that cross each other, were selected for tower crane design in virtual environment. Within virtual environment, the steel S275 was assigned to the beams. This material is a readily weldable low carbon manganese steel with good impact 
resistance (including in sub-zero temperatures). It is commonly supplied in the untreated or normalised condition and is available in several variations, which offer slight modifications of chemical composition and mechanical properties. [11]

Designed crane was loaded by the weight of wire rope hoist, by the load of lifted up weight of $4000 \mathrm{~kg}(39.24 \mathrm{kN})$ positioned centrally and by the weight of individual bars. Balancing load of the crane is achieved in real practice by concrete slabs fixed to the short crane arm that is calculated based on the moment equation. Its value is $3500 \mathrm{~kg}(34.34 \mathrm{kN})$.

Analysis has shown not only the most deformed bars (in Figure 5a are red coloured), but also the value of maximal stress that is $619.23 \mathrm{MPa}$.

The achieved value exceeds not only due to the maximum tensile strength given by a standard EN 10025-2 (470-610) MPa. That is why it was necessary to rebuild the crane and to add next bars (as it is shown in Fig. 5b) to be the crane more rigid. The crane was analysed again and after redesigning, no deformations were evident and the stress value decreased in $397.58 \mathrm{MPa}$.

a)

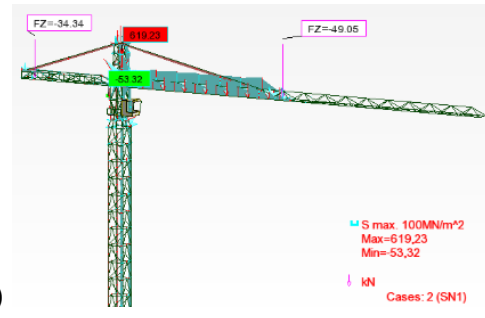

b)

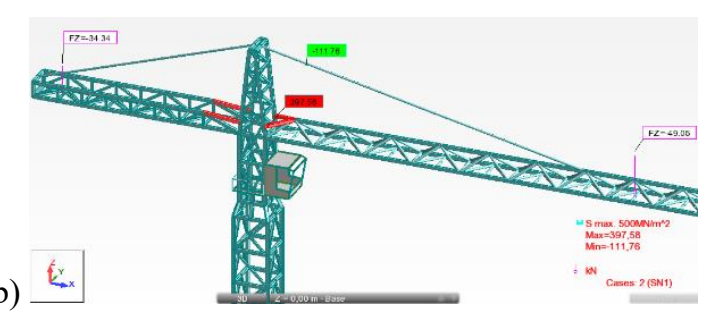

Fig. 5. Static analysis of crane a) the maximum allowable stress of bars was achieved; b) additional bars to be the crane more rigid.

It needs to be said that the real value of the load needs to consider a safety factor of a crane. Minimum safety factor for cranes and derricks is "6" [12], so the beams of crane need to be more rigid. Due to this reason the type of bars has been re-designed. Their crosssection has been changed on closed square type, sizes $80 \times 80 \times 8 \mathrm{~mm}$, while the area increased twice from $5.41 \mathrm{~mm}^{2}$ to $20.84 \mathrm{~mm}^{2}$.

\section{Conclusions}

Cranes and other equipment used for lifting are an important part of many manufacturing processes. The correct analysis before putting the crane into operation will ensure that the crane remains in good working condition and that all activities will run safely and smoothly.

Static analysis of the tower crane presented in the article has been focused on the truss structure of tower crane design to be possible to lift up the specified weight. Preliminary study used due to verification of boundary conditions in selected software application showed that the values obtained by both methods (computational and analytical - using the selected software Robot Structural Analysis) are comparable. The small differences in the values have been caused by using different decimal places of numbers within computation. Investigation of designed tower crane has followed. It has been found out that the stresses in some beams of the crane structure exceed the maximum tensile strength given by a standard and the tower crane beams have been redesigned. Finally, the cross-section of the beams has been also modified to be strength conditions satisfied considering the safety factor. It has been stated that the static analysis is only the base for next analyses such as e.g. dynamic analysis (when the load moves in relation to the structure of the crane) or modal analysis of the truss. 
Acknowledgement. The present contribution has been prepared with direct support of Ministry of Education, Science, Research and Sport of SR through the project KEGA 007TUKE-4/2018.

\section{References}

1. K. Monkova, P. Monka, S. Hloch: Inverse Processing of Undefined Complex Shape Parts from Structural High Alloyed Tool Steel, Adv in Mech Engineering, art. num. 478748, (2014)

2. J. Petru, T. Zlamal, R. Cep, K. Monkova, P. Monka: Influence of cutting parameters on heat-affected zone after laser cutting, Tech. Gazette, 20, 2, 225-230 (2013)

3. P. Monka, K. Monkova, V. Modrak, S. Hric, P. Pastucha: Study of a tap failure at the internal threads machining, Eng Failure Analysis, 100, 25-36 (2019)

4. L. Misik, S. Hloch, A. Vagaska, K. Monkova: Side milling factors analysis affecting the surface irregularities of high-grade steel E295, Tech Gazette, 15, 2, 19-23 (2008)

5. K. Monkova, P. Monka, S. Hloch, J. Valicek: Kinematic analysis of quick-return mechanism in three various approaches, Tech Gazette, 18, 2, 295-299 (2011)

6. J. Valicek, S. Hloch, S. Fabian, K. Monkova, M. Hatala, A. Luptakova, A. Radvanska: Analysis of signals obtained from surfaces created by abrasive waterjet by means of amplitude-frequency spectra and autocorrelation function, Tech Gazette, 15, 1, 25-31 (2008)

7. P. Hreha, S. Hloch, P. Monka, K. Monkova, L. Knapcikova, P. Hlavacek, M. Zelenak, I. Samardzic, D. Kozak: Investigation of sandwich material surface created by abrasive water jet (AWJ) via vibration emission, Metalurgija, 53, 1, 29-32 (2014)

8. K. Monkova, I. Zetkova, L. Kucerova, M. Zetek, P. Monka, M. Dana: Study of 3D printing direction and effects of heat treatment on mechanical properties of MS1 maraging steel, Archive of Applied Mechanics, 89, 5, 791-804 (2019)

9. P. Monka, K. Monkova, M. Balara, S. Hloch, J. Rehor, A. Andrej, M. Somsak: Design and experimental study of turning tools with linear cutting edges and comparison to commercial tools, Int J of Adv Manuf Technology, 85, 9-12, (2016)

10. A. Radvanska, J. Petru, K. Monkova, T. Zlamal, P. Hreha, M. Somsak, A. Andrej, B. Safran: Rationalization of manufacturing of plastic injection moulds by abrasive waterjet, Tech Gazette, 22, 2, pp. 521-525 (2015)

11. A. Smeringiova, I. Vojtko, K. Monkova: Experimental analysis of the dynamics of gear boxes - Part 1, Technisches Messen, 82, 2, 57-64 (2015)

12. K. Monkova, P. Monka: Newly Developed Software Application for Multiple Access Process Planning, Adv in Mech Engineering, Article Number 539071, (2014) 